\title{
ENHANCED FEATURE EXTRACTION ALGORITHMS USING OSCILLATORY-MODE PULSED EDDY CURRENT TECHNIQUES FOR AIRCRAFT STRUCTURE INSPECTION
}

\author{
Iuliia Lysenko $^{1^{*}}$ (DD 0000-0001-9110-6684 \\ Yurii Kuts ${ }^{1}$ (D) 0000-0002-8493-9474 \\ Anatoliy Protasov $^{1}$ (iD 0000-0002-2965-3334 \\ Mykhailo Redka ${ }^{1}$ (D) 0000-0002-0374-2208 \\ Valentin Uchanin ${ }^{2}$ (i) 0000-0001-9664-2101 \\ ${ }^{1}$ Department of Non-Destructive Testing Instruments and Systems, Faculty of Instrumentation \\ Engineering, National Technical University of Ukraine "Igor Sikorsky Kyiv Polytechnic Institute", \\ 37, Prosp. Peremohy, Kyiv, Ukraine, 03056 \\ ${ }^{2}$ Karpenko Physico-Mechanical Institute of the National Academy of Sciences of Ukraine, \\ 5, Naukova St., Lviv, Ukraine, 79060 \\ *j.lysenko@kpi.ua
}

\begin{abstract}
A review of the existing literature shows that modern pulsed eddy current (PEC) technique for flaw detection in aircraft structure inspection is typically carried out in aperiodic mode. At the same time, the unstable characteristic points of the EC signal usually used as informative parameters can restrict the potential of this excitation mode due to significant measurement errors.

This article considers an advanced PEC method of NDT based on the oscillatory mode. To obtain the conditions concerned with different modes of EC probe response oscillations, an equivalent scheme of the "testing object - EC probe" system was developed and analyzed. The frequency and attenuation coefficient of natural oscillations are proposed as the informative parameters of the probe signals. The obtained mathematical model of the probe signals allows for the dependence of proposed signal parameters on the characteristics of the testing object to be evaluated.

Herein, we first develop algorithmic software for determining and analyzing the discrete amplitude and phase characteristics of PEC NDT signals based on the simulation results. The errors of the natural frequency oscillations and the attenuation coefficient determination as well as the optimal time for its determination are analyzed in order to minimize the possible errors. Next, the proposed informative parameters are experimentally investigated using a set of specimens. The obtained results confirm the possibility of the proposed methodology to enhance the inspection procedures related to the electrical conductivity and geometric parameters measurements as well as the detected defect sizing.
\end{abstract}

Keywords: pulsed eddy current, natural oscillation frequency, attenuation, amplitude and phase signal characteristics

Type of the work: Research Article 


\section{INTRODUCTION}

Eddy current non-destructive testing (EC NDT) is a technique for surface inspection and flaw detection, based on the use of a variable electromagnetic field and the excitation of eddy currents in a tested object (TO) fabricated from electrically conductive material [1]. It is widely used in aviation due to its high certainty, reliability, and practicability for aircraft structure inspection [2]. Nowadays, EC NDT is seeing rapid development, due to an improved excitation mode and the application of new informative parameters in combination with enhanced methods applied for information signals processing [3].

The most common methods of EC NDT are based on the use of harmonic signals to excite the electromagnetic field and the analysis of such informative signal parameters as amplitude and phase [4]. Other methods, such as ones based on pulsed excitation of eddy currents, are being increasingly included into EC NDT practice [5].

The use of pulsed excitation mode to evaluate the thickness of a metal coating on a metal substrate was analyzed in the first experiments with pulsed eddy current (PEC) NDT [6]. The experimental system consisted of a pulse generator to excite the bridge circuit, two identical probes, and an oscilloscope for visualization and analysis of the result. One of the probes was placed near the calibration specimen and the other near the test specimen. Evaluation of the result was performed by determining the horizontal displacement of the nodal point of the oscilloscope beam. After that, the procedure of balancing the component signals of both probes using a bridge circuit was used to increase the sensitivity [7]. The probes used in this experiment consisted of a solenoid winding on a ferrite core with a cylindrical ferrite package around it. The influence of the gap between the TO and probe on the position of the nodal point on the oscillogram was also analyzed [8].

Further studies were devoted to the development of systems that simultaneously determine the distance between the eddy current probe (ECP) and TO, and the TO parameters and characteristics. For example, papers $[9,10]$ describe a system based on the use of a short length pulse to obtain information about the distance between the probe and TO, and a pulse of much greater length to penetrate a metal object to obtain information about defects inside.

Subsequently, to increase the accuracy of measuring TO parameters such as electrical conductivity and thickness, researchers proposed a pulse induction method [11], in which eddy currents were excited by a pulse of field strength as $t^{n} \cdot I(t)$, where $t$ - time, $n=0$ or $1, I(t)-$ unit function. Conclusions about the value of the TO parameters were made over the time interval $T$ from the beginning of the pulse until it reached a certain threshold level. In the case of 0.3 threshold level, a functional dependence between the TO specific conductivity and the $T$ value was obtained.

In paper [12], the combined use of harmonic and pulsed modes of electromagnetic field excitation is considered to evaluate the thickness of pipe walls. This was proposed to increase the number of testing parameters. The positive effect was achieved due to the use of informative parameters, such as the value of the ECP signal amplitude and the change of the time position of the zero-crossing point by this signal. The wall thickness of the ferromagnetic tube was determined by the time the information signal crosses the zero level, and the inner diameter of the pipe was determined by the signal amplitude value.

An experimental study of the EC NDT pulse mode, which was used to evaluate the degree of corrosive attack to the metal, is presented in studies [13, 14]. Both publications are based on the estimation of the time position of the zero-crossing point by the ECP signal. The authors consider the possibilities of developing a system of PEC NDT, analysis methods of ECP signals [13], and visualization methods of results [14].

In study [15], to evaluate the sensitivity of EC NDT to the detection of inclusions, a comparison of two methods of EC NDT (traditional harmonic and pulse) was performed. This research was carried out on specially made specimens of titanium alloy with artificial defects that were flat-bottomed cylinders with 
different diameters. In the case of harmonic excitation, an absolute probe was used, and in the case of pulsed excitation, a probe with an excitation coil $4 \mathrm{~mm}$ in diameter and a smaller measuring coil located inside it was used. According to the experiment results, it was concluded that the use of the peak value of the amplitude in the case of probe pulsed excitation is not sufficient to increase the resolution compared to harmonic excitation. Also, due to the use of such an informative parameter as amplitude, it is not possible to increase the sensitivity of EC NDT. The authors emphasize that PEC NDT needs further research and improvement in the probe design and signals analysis methods.

Another study [16] looked at the influence of parameters of the ECP-TO system, represented by the equivalent circuit, on the information signal shape and signal parameters in the conditions of excitation of the ECP by the pulse signal. These authors proposed criteria for selecting the parameters and characteristics of the excitation and measuring ECP coils to obtain the maximum penetration depth of eddy currents into the TO and the optimal signal-to-noise ratio. The influence of the ECP coil parameters on the voltage peak value of the information signal, which depends on the depth of the defect in the TO, was found by combining different ECP coils parameters. The obtained results indicate that the ECP configuration has to be taken into account to increase the testing depth when pulsed excitation is used. It was also found that using modern methods of signal processing and analysis may yield an improvement in the sensitivity of PEC techniques.

Interesting research is also presented in paper [17] by an international team of scientists from the United States, China, and Italy, looking at PEC application to detecting defects in the fixation holes in aircraft structure. It is known that the main problem with inspecting such objects is the difficulty of detecting defects in the holes used to connect several layers of metal. Therefore, GMR probes (giant magneto-resistance) were used and the obtained signals were analyzed in the time and frequency domain with following plotting an A- and C-scans. When analyzing the probe signal in the time domain, the peak value of the signal amplitude was chosen as an informative parameter. The amplitude values were used to plot a C-scan, which has a minimum and maximum values, the symmetry of which relative to each other can be used to detect defects. The authors also proposed to use the difference between the signal amplitude values to detect subsurface defects in the TO. The analysis of the probe signal in the frequency domain was based on the Fourier transform and fully confirmed the results of the C-scan obtained using amplitude values. Thus, all conclusions about the TO parameters were based on one informative parameter: the maximum amplitude values for time analysis, the maximum spectrum energy for frequency analysis.

Study [18] presented a new feature, called the rising point time, that can be obtained from the PEC NDT technique. This feature was proposed to identify the different defect types and lift-off. It has offered some benefits: independence of coil dimensions and the ability to detect the defect depth regardless of the defect type or shape.

A new approach for defect classification and quantification by using the PEC probe and integration of principal components analysis and wavelet transform for feature-based signal interpretation is given in paper [19], where the analysis of PEC signals in aperiodic mode was also used. For defect classification and quantification, different features were extracted from the PEC signals.

The PEC NDT techniques are also used extensively for the detection of hidden cracks, corrosion in multi-layer conductive structures, etc. Study [20] demonstrated the ability of a scanning PEC system to detect and discriminate corrosion in multi-layer metal aircraft structures. Two main features of the signal were used in flaw characterization. It was demonstrated that the peak amplitude value is proportional to the amount of metal loss and the zero-crossing point of the signal contains information about the depth of the flaw in the structure. Other research, presented in paper [21], shows the application of a PEC system to identify and characterize atmospheric corrosion on steel specimens. Time-domain PEC signal features were extracted to determine the changes in the electrical conductivity and permeability of the corroded steel area. 
Paper [22] analyzed the PEC probe response to applied stress to heat-treatable and non-heat-treatable aluminum alloys. Specimens of aluminum alloys with different levels of plastic deformation were subjected to elastic uniaxial tension. The results suggested that it was possible to measure the maximum difference between the PEC signal at TO under stress and without it and to identify the effect of applied stress. Other researchers have proposed PEC techniques to detect fatigue cracks, which often appear in the aircraft riveted structures $[23,24]$. A dual polarity low-frequency pulse is used to excite the coil. The techniques are based on the time-domain signal analysis in different time-slices. In studies [23, 24] both techniques - peak amplitude value and zero-crossing time of signal in the time domain - are used as key features.

The recently developed ISO 206692017 standard [25], which is entirely devoted to PEC NDT, testifies to the intense interest in the technique. According to [25], PEC NDT is recommended for measuring the thickness of ferromagnetic sheet materials with and without an insulating layer. The method is recommended to inspect the thinning of the TO wall, which is caused by a large area of corrosion, and without removing the coating from it. This standard applies to the inspection of ferromagnetic objects which are made of carbon and low-alloy steel. The temperature range during the operation of the equipment is $196-500^{\circ} \mathrm{C}$ (temperature estimated at the surface). The possible range of TO wall thickness is from $3 \mathrm{~mm}$ to $65 \mathrm{~mm}$; the range of coating thicknesses is from $0 \mathrm{~mm}$ to $200 \mathrm{~mm}$. Pipes with a diameter of more than $50 \mathrm{~mm}$ may be tested, a limitation due to the high sensitivity to the geometry of the TO surface.

Overall, numerous studies in this literature review have shown that aperiodic mode is usually used in PEC inspection. In this case, the various time-domain features (time to peak amplitude, peak amplitude value, rising point, and zero-crossing point) extracted from the PEC probe response are used to characterize the test object. However, these parameters are unstable to noise influence, which leads to a significant measurement error, and it does not allow the full potential of the PEC technique to be realized.

In the present study, the PEC technique based on the oscillatory mode was analyzed as a promising tool to obtain enhanced feature extraction algorithms facilitating improved aircraft structure inspection.

\section{THEORETICAL PART}

\subsection{Analysis of the PEC probe impedance in idling mode}

The system of inductively coupled electrical circuits has been used to analyze the formation processes of information signals in the ECP-TO system. First, let consider the equivalent circuit of single-coil ECP with pulse excitation in idling mode. It is shown in Fig. 1, where $u_{G}(t)$ - pulse generator signal, $R$ - the generator output resistance, $C_{1}$ - the total capacitance formed by the turn-to-turn capacitance of the coil and other probe parasitic capacitances, $R_{1}$ - the coil active resistance, $L_{1}$ - the coil inductance, $i_{1}, i_{2}$ and $i_{3}$ - the currents in the corresponding branches of the circuit. It is important to take into account the capacity of $C_{1}$, which significantly affects the formation of the PEC signal in the oscillatory mode.

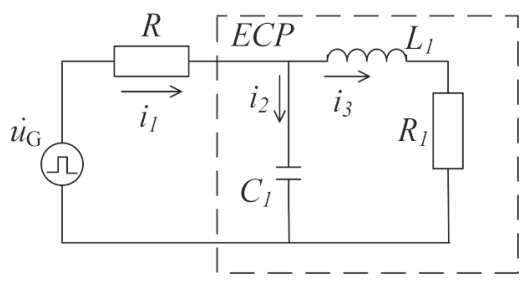

Fig. 1. Equivalent circuit of the pulsed ECP connected to the pulse generator. 
The power supply voltage $u_{G}(t)$ is a periodic pulse sequence of rectangular shape:

$u_{\mathrm{G}}(t)=\left\{\begin{array}{l}u_{0}, \quad t \in n \cdot T_{p}+\tau, n=0,1,2 \ldots \\ 0, \quad t \notin n \cdot T_{p}+\tau,\end{array}\right.$

where $u_{0}, T_{p}, \tau$ - the amplitude, period, and duration of the pulses, respectively.

Under the condition of single-coil ECP pulsed excitation, to determine its response to the fronts of the exciting pulse signal, the transient response analysis in the ECP circuit is performed. The analysis is based on the solution of the characteristic equation, which corresponds to the expression of the input complex resistance of the electric circuit at alternating current.

The input complex resistance for the single-coil ECP equivalent circuit (Fig. 1) takes the form:

$$
\dot{Z}_{e q}(\omega)=R+\frac{R_{1}+i \omega L_{1}}{1+R_{1} i \omega C_{1}+(i \omega)^{2} L_{1} C_{1}} .
$$

Corresponding to (2) the characteristic equation could be written as:

$R Z_{1} C_{1} \cdot p^{2}+\left(R R_{1} C_{1}+L_{1}\right) \cdot p+R+R_{1}=0$

where $p$ - parameter of the characteristic equation, $p=i \omega, i=\sqrt{-1}$.

The solution of the quadratic equation (3) is the roots of the form:

$p_{1,2}=-\frac{R R_{1} C_{1}+L_{1}}{2 R L_{1} C_{1}} \pm \sqrt{\frac{\left(R R_{1} C_{1}+L_{1}\right)^{2}}{4 R^{2} L_{1}^{2} C_{1}^{2}}-\frac{R+R_{1}}{R L_{1} C_{1}}}$.

In the calculations of transient response, the total current of the circuit is taken to be equal to the sum of the forced and free currents. The forced current is set by the power supply of the electrical circuit. This component does not contain information about the properties of TO, so it is not of interest to the ECP signals analysis. The free current has a damping character in time and is described by such components: $A e^{\alpha t}$, where $\alpha$-where is the attenuation coefficient, which depends on the circuit parameters, and it can be determined through the roots of the characteristic equation.

Depending on the ratio of the components $\left(R R_{1} C_{1}+L_{1}\right)^{2} / 4 R^{2} L_{1}^{2} C_{1}^{2}$ and $R+R_{1} / R L_{1} C_{1}$ in equation (4), there are three possible types of roots $p_{1}$ and $p_{2}$ of equation (3) and, accordingly, three variants of expressions to represent the components of the free current component.

The critical circuit resistance (at which the circuit begins aperiodic discharge) is equal to:

$R_{c r}=\frac{R_{1} C_{1} L_{1} \pm 2 L_{1} \sqrt{L_{1} C_{1}}}{R_{1}^{2} C_{1}^{2}-4 L_{1} C_{1}}$.

There are three options for choosing the resistor $R$ in the scheme in Fig. 1:

1) $R>R_{c r}$, roots $p_{1}$ and $p_{2}$ are real, $p_{1} \neq p_{2}$, negative, and correspond to the attenuating current as:

$i_{\text {free }}(t)=A_{1} e^{p_{1} t}+A_{2} e^{p_{2} t}, \quad p_{1}, p_{2}<0, \quad t \in T_{a}, \quad A_{1}, A_{2}>0$,

where $T_{a}$ - analysis time, $T_{a}<T_{p}, A_{1}$ and $A_{2}$ - integration constants;

2) $R=R_{c r}$, roots are real, $p_{1}=p_{2}$, negative, which correspond to the attenuating current as:

$i_{\text {free }}(t)=\left(A_{1}+A_{2} t\right) e^{p_{1} t}, \quad p_{1}=p_{2}<0, \quad t \in T_{a}, \quad A_{1}, A_{2}>0$, 
3) $R<R_{c r}$, the roots are complexly conjugated, with a negative real part of the form $p_{1,2}=-\alpha \pm i \omega_{0}$, where $\alpha>0$ - attenuation coefficient, $\omega_{0}$ - angular frequency of natural oscillations corresponding to the current in the form of attenuating harmonic oscillations:

$i_{\text {free }}(t)=A e^{-\alpha t} \sin \left(\omega_{0} t+v\right), \quad p_{1,2}=-\alpha \pm j \omega_{0}, \quad t \in T_{a}>\alpha^{-1}, \quad A>0$,

where $A$ - integration constant, $v$ - initial phase.

For the oscillatory mode, the characteristic equation roots are complexly conjugated, and the free current component is represented by an attenuating harmonic oscillation with angular frequency $\omega_{0}$ and attenuation $\alpha$ :

$\omega_{0}=\sqrt{\frac{R+R_{1}}{R L_{1} C_{1}}-\frac{\left(R R_{1} C_{1}+L_{1}\right)^{2}}{4 R^{2} L_{1}^{2} C_{1}^{2}}}, \quad \alpha=\left(R R_{1} C_{1}+L_{1}\right) / 2 R L_{1} C_{1}$.

The voltage reduction on the ECP is determined by the formula:

$u(t)=u_{0} \cdot f\left(t-\tau_{0}\right)+A e^{-\alpha t} \sin \left(\omega_{0} t+v\right), \quad t \in T_{a} \gg \alpha^{-1}, \quad \tau_{0} \in T_{a}, \quad A>0$,

where $f\left(t-\tau_{0}\right)$ - unit step function.

The formula (10) at $t=0$ is of the form:

$u(t=0)=u_{!_{1}}(t=0)-u_{0} \cdot f\left(t-\tau_{0}\right)=A \cdot \sin (v)$,

where $u_{C_{1}}(t=0)$ - the voltage on the capacitor $C_{1}$ at $t=0$. If the constant integration and the initial phase are determined formula $(10)$ is of the form:

$u(t)=u_{0} \cdot f\left(t-\tau_{0}\right)+\left(u_{!_{1}}(0)-u_{0} \cdot f\left(t-\tau_{0}\right)\right) e^{-\alpha t} \frac{\sqrt{\alpha^{2}+\omega_{0}^{2}}}{\omega_{0}} \sin \left(\omega_{0} t+\operatorname{arctg}\left(\frac{\alpha}{\omega_{0}}\right)\right)$.

\subsection{Analysis of processes in the "single-coil ECP - non-magnetic TO" system}

Based on the general rules and methods of linear electric circuits calculation, the "single-coil ECP non-magnetic TO" system is represented by an equivalent scheme shown in Fig. 2a. On the equivalent scheme non-magnetic TO is presented by series-connected elements $R_{2}(\bar{w})$ and $L_{2}(\bar{w})$, which depend on the vector $\bar{w}$ of TO parameters and characteristics, and an inductive connection between coils $L_{1}$ and $L_{2}(\bar{w})$ is added.

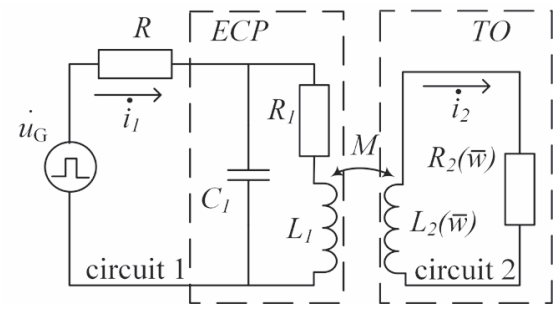

a)

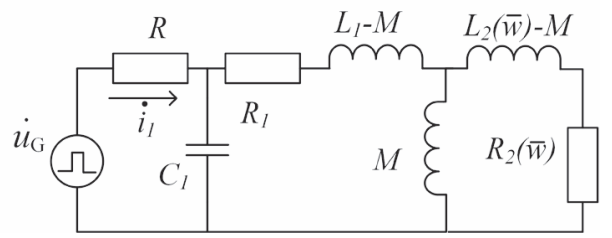

b) 


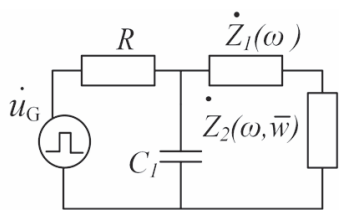

c)

Fig. 2. Equivalent scheme of the "ECP - non-magnetic TO" system (a), after the solution of inductive circuits (b) and after its simplification (c).

After solving the inductive circuits, the scheme in Fig. 2a is presented as shown in Fig. $2 \mathrm{~b}$ and then simplified to the scheme in Fig. $2 c$ with the following parameters:

$$
\begin{aligned}
& \dot{Z}_{1}(\omega)=R_{1}+i \omega\left(L_{1}-M\right), \quad \dot{Z}_{2}(\omega, \bar{w})=\frac{\dot{Z}_{3}(\omega, \bar{w}) i \omega M}{\dot{Z}_{3}(\omega, \bar{w})+i \omega M}, \\
& \dot{Z}_{3}(\omega, \bar{w})=R_{2}(\bar{w})+i \omega\left(L_{2}(\bar{w})-M\right) .
\end{aligned}
$$

The input resistance for the equivalent circuit of the "single-coil ECP - non-magnetic TO" (Fig. 2c) is determined by the expression:

$$
\dot{Z}_{e q}(\omega, \bar{w})=R+\frac{\dot{Z}_{1}(\omega)+\dot{Z}_{2}(\omega, \bar{w})}{1+\dot{Z}_{1}(\omega) i \omega C_{1}+\dot{Z}_{2}(\omega, \bar{w}) i \omega C_{1}} .
$$

The corresponding characteristic equation of the electric circuit is an equation of the 3rd order, written as:

$$
\begin{aligned}
& C_{1} R\left(L_{1} L_{2}(\bar{w})-M^{2}\right) p^{3}+\left(C_{1} R L_{1} R_{2}(\bar{w})+C_{1} R_{1} L_{2}(\bar{w}) R+L_{1} L_{2}(\bar{w})-M^{2}\right) p^{2}+ \\
& +\left(L_{2}(\bar{w}) R+C_{1} R_{1} R_{2}(\bar{w}) R+L_{2}(\bar{w}) R_{1}+L_{1} R_{2}(\bar{w})\right) p+R R_{2}(\bar{w})+R_{1} R_{2}(\bar{w})=0,
\end{aligned}
$$

or in general:

$$
A p^{3}+B p^{2}+C p+D=0
$$

with coefficients: $A=C_{1} R\left(L_{1} L_{2}(\bar{w})-M^{2}\right), \quad B=C_{1} R L_{1} R_{2}(\bar{w})+C_{1} R_{1} L_{2}(\bar{w}) R+L_{1} L_{2}(\bar{w})-M^{2}$, $C=L_{2}(\bar{w}) R+C_{1} R_{1} R_{2}(\bar{w}) R+L_{2}(\bar{w}) R_{1}+L_{1} R_{2}(\bar{w}), \quad D=R R_{2}(\bar{w})+R_{1} R_{2}(\bar{w})$.

In the latter expressions, the functional dependence of coefficients A, B, C, D on the vector of TO parameters $\bar{w}$ is not specified, for the sake of simplification.

Typically, the Cardano formula is applied to determine the roots of a cubic equation in the domain of complex numbers. According to this equation (16) could be represented in canonical form:

$$
y^{3}+b y+q=0
$$

where $b=\left(3 A C-B^{2}\right) / 3 A^{2}, \quad q=\left(2 B^{3}-9 A B C+27 D A^{2}\right) / 27 A^{3}$. 
The discriminant of the cubic equation (17) is defined as:

$\Delta=\left(\frac{q}{2}\right)^{2}+\left(\frac{p}{3}\right)^{3}=\frac{\left(2 B^{3}-9 A B C+27 D A^{2}\right)^{2}}{2916 A^{6}}+\frac{\left(3 A C-B^{2}\right)^{3}}{729 A^{6}}$.

Under the condition $\Delta>0$, equation (17) has one real and two complex conjugate roots:

$y_{1}=\sqrt[3]{-q / 2+\sqrt{\Delta}}+\sqrt[3]{-q / 2-\sqrt{\Delta}}$,

$y_{2,3}=-0,5(\sqrt[3]{-q / 2+\sqrt{\Delta}}+\sqrt[3]{-q / 2-\sqrt{\Delta}}) \pm j \frac{\sqrt{3}}{2}(\sqrt[3]{-q / 2+\sqrt{\Delta}}-\sqrt[3]{-q / 2-\sqrt{\Delta}})$

The solutions of equation (16) are the next roots: $p_{1}=y_{1}-B / 3 A, p_{2}=y_{2}-B / 3 A, p_{3}=y_{3}-B / 3 A$.

In the case of such roots as (20), the ECP current has the form of attenuating harmonic oscillation, and therefore the roots of the characteristic equation have a general form $p_{1,2}(\bar{w})=$ $=-\alpha(\bar{w}) \pm i \omega_{0}(\bar{w})$, which are similar to the ones obtained in 2.1 .

Thus, the interaction of TO with the coil field leads to a change in its electrical parameters (active resistance and inductance), which affect three parameters - the attenuation coefficient $\alpha$, natural frequency $\omega_{0}$, and the initial phase $v$ (when reference frequency signal is using). Therefore, these parameters can be used in PEC with oscillation mode for feature extraction.

\subsection{Analysis of processes in the "single-coil ECP - magnetic TO" system}

It has been proposed that the equivalent circuit of the magnetic TO can be represented as an $R L C$ circuit, which formally corresponds to the received ECP signals [26]. Therefore, the equivalent scheme of the "ECP - magnetic TO" system can be represented by elements $R_{2}(\bar{w}), C_{2}(\bar{w})$ and $L_{2}(\bar{w})$, with the inductive connection between coils $L_{1}$ and $L_{2}(\bar{w})$ (Fig. 3a). The equivalent circuit in Fig. 3b is simplified Fig. 3a by the method of solving inductive circuits. The elements of this circuit are determined by the formulas:

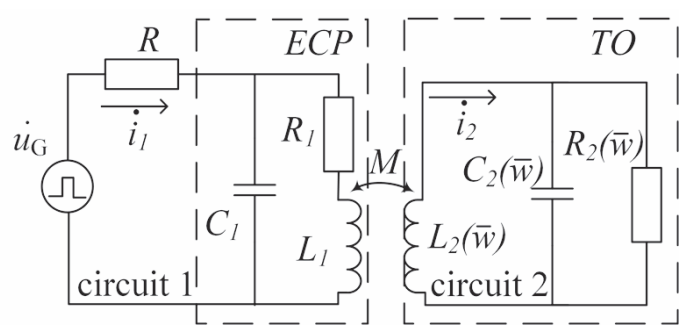

a)

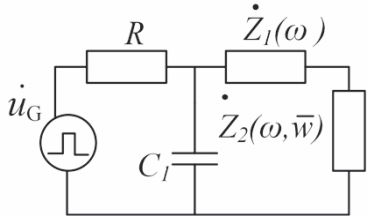

b)

Fig. 3. Equivalent scheme of "ECP - magnetic TO" system (a) and its simplification (b).

$\dot{Z}_{1}(\omega)=R_{1}+i \omega\left(L_{1}-M\right)$

$\dot{Z}_{2}(\omega, \bar{w})=\dot{Z}_{3}(\omega, \bar{w}) i \omega M /\left(\dot{Z}_{3}(\omega, \bar{w})+i \omega M\right)$,

$\dot{Z}_{3}(\omega, \bar{w})=R_{2}(\bar{w}) /\left(1+i \omega C_{2}(\bar{w}) R_{2}(\bar{w})\right)+i \omega\left(L_{2}(\bar{w})-M\right)$. 
The input resistance for the equivalent circuit of the "single-coil ECP - magnetic TO" (Fig. 3b) is determined by the expression:

$$
\dot{Z}_{e q}(\omega, \bar{w})=R+\frac{\dot{Z}_{1}(\omega)+\dot{Z}_{3}(\omega, \bar{w})}{1+\dot{Z}_{1}(\omega) i \omega C_{1}+\dot{Z}_{3}(\omega, \bar{w}) i \omega C_{1}} .
$$

In this case, the characteristic equation is of the 4th order and may be solved using known mathematical transformations (for example, through the resolvent, according to the Descartes-Euler formula or the Ferrari method [27]). The roots that are solutions of the 4th order equation can also be represented as $p_{1,2}(\bar{w})=-\alpha(\bar{w}) \pm i \omega_{0}(\bar{w})$.

\subsection{Algorithm for determining the attenuation and natural frequency of the PEC signals}

The algorithm structure for determining the attenuation and natural frequency of the PEC signals in idle mode is shown in Fig. 4 in a general form. The attenuation and the natural oscillation frequency are calculated according to the amplitude and phase of the signal type (10), which are obtained by the Hilbert transform $[28,29]$. The general method of obtaining the discrete amplitude and discrete phase of the signal as a function of time for ECP has been discussed in [30].

The sampling unit of the ECP signal in the conditions of pulse excitation mode provides for the selection of the attenuating harmonic oscillation interval, which is equal to several periods and ends before the ECP signal level becomes less the level of noise and interference. The ECP signal analysis unit enables the Hilbert image of these signals to be determined in order to obtain discrete ECP signals amplitudes and phases [31].

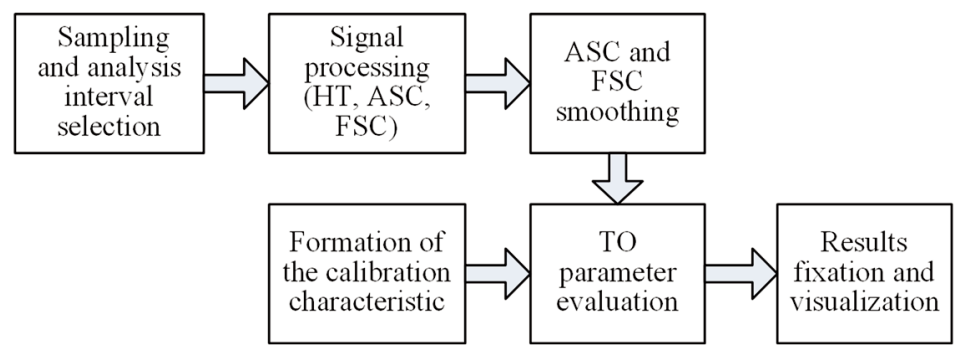

Fig. 4. The algorithm structure for determining the attenuation and natural frequency of the PEC signals.

In order to increase the accuracy of determining the informative ECP signals parameters, the application of amplitude and phase signal characteristics (ASC and FSC) smoothing methods is provided in the next blocks: for amplitude - application of exponential approximation, for phase determination of linear trend. Also, to increase the accuracy of determining the attenuation of the ECP signal, an iterative method is used to determine the optimal analysis interval of this characteristic, taking into account the condition $\Delta T \alpha \approx 1.1089[31,32]$.

The evaluation unit of the TO parameters performs their determination using the informative parameters of the ECP signals by comparing them with similar parameters of the standard specimens. The results can be displayed in digital and graphical forms. 


\section{AN EXPERIMENTAL INVESTIGATION OF THE PROPOSED INFORMATIVE PARAMETERS FOR PEC INSPECTION}

\subsection{Evaluation of the dielectric coating thickness on an electrically conductive substrate}

Experimental research was performed in two stages. In the first stage, the influence of the characteristics of the uncoated TO material on the parameters of PEC probe signals was analyzed. The TOs were flat specimens made of aluminum, bronze, and steel (specific conductivity $\gamma_{a l}=4.87 \cdot 10^{7} \mathrm{~S} / \mathrm{m}, \gamma_{b r}=2.75 \cdot 10^{7} \mathrm{~S} / \mathrm{m}, \gamma_{s t}=1.45 \cdot 10^{6} \mathrm{~S} / \mathrm{m}$ ) with a thickness exceeding the depth of eddy currents penetration (Fig. 5). In the second stage, the influence of the dielectric coating thickness TO on the frequency and signal attenuation was analyzed [33].

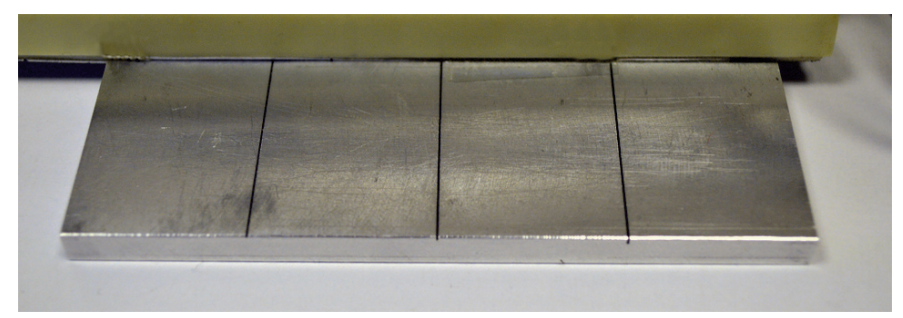

Fig. 5. The flat aluminum specimen (tested object).

The primary coil $\left(W_{1}=80\right)$ of the ECP received an exciting pulse signal from the current generator of the form:

$i(t)=\left\{\begin{array}{l}5 \mathrm{~mA}, \quad t_{1}+k T_{n}<t<t_{1}+\tau+k T_{n} \\ 0 \mathrm{~A}, \quad t_{1}+\tau+k T_{n}<t<t_{1}+T_{n}(k+1), \quad k=0,1,2 \ldots\end{array}\right.$

where $T_{n}=125 \cdot 10^{-6} \mathrm{~s}-$ the signal period, $\tau=62.4 \cdot 10^{-6} \mathrm{~s}-$ signal duration.

The signal of the measuring coil $\left(W_{2}=420\right)$ was amplified and digitized by the analog-to-digital converter (ADC). Signal sets $u[j], j=\overline{1, \ldots 10000}$ were obtained. Discretization was performed with the period $T_{d}=4 \cdot 10^{-9} \mathrm{~s}$.

The signal from the middle part of the set was used to smooth the information signal phase. For the specimen made of aluminum and bronze, it was $j_{a l}=j_{b r}=\overline{1500 \ldots 6000}$, for the specimen of steel, $j_{s t}=\overline{1500 \ldots 3501}$. Fragments of ECP signals obtained on test specimens without coatings are shown in Fig. 6a. There are different values of electrical conductivity and magnetic permeability of materials that lead to changes in frequency and attenuation of the ECP signal. Fig. 6b shows fragments of signals in the case of testing the aluminum specimen with different dielectric coating thicknesses. Curve 1 corresponds to the ECP signal in the TO without coating, curve $2-$ coated $h=0.565 \mathrm{~mm}$, curve 3 $h=4.90 \mathrm{~mm}$. Fig. $6 \mathrm{~b}$ shows that the effect of eddy currents on the information signal ECP decreases with increasing $h$. The amplitude values of the signal increases and the oscillations frequency is changed.

Fig. 7a shows $\alpha(h)$ functions that indicate an increase in the attenuation of PEC probe signals case decreasing $h$. Therefore, the dependence of $\alpha(h)$ for specimens made of magnetic and nonmagnetic materials is exponential. The characteristics of the specimens' material also affect the signal attenuation rate. A slight deviation of the result from the exponential dependence can be caused by the latent defects, changes in the specimens' characteristics, errors in measuring the thickness of the coating or attenuation, and others. 


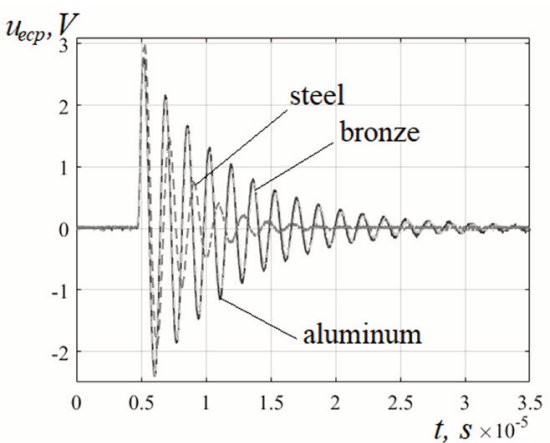

a)

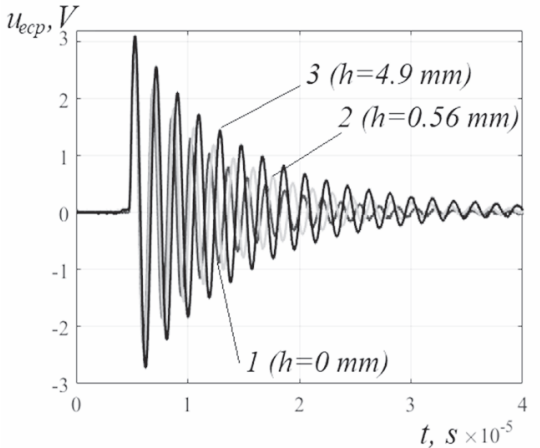

b)

Fig. 6. ECP signals for different TO materials (a) and for aluminum TO with different coating thickness.

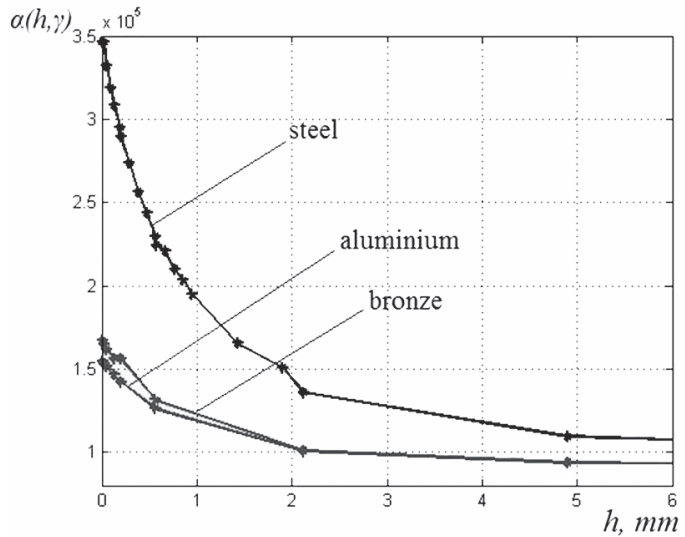

a)

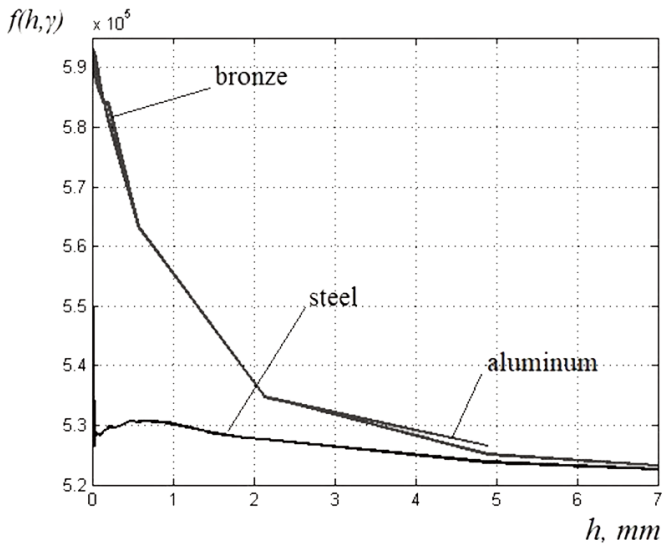

b)

Fig. 7. Graphs $\alpha(h)$ (a) and $f(h)$ (b) for different specimen materials.

The results of determining the ECP signals frequency as a function of the dielectric coating thickness are shown in Fig. 7b. The $f(h)$ dependence gives an unambiguous result only for nonmagnetic materials. In this case, the sensitivity to the coating thickness increases with decreasing size. 


\subsection{Testing of electrical conductivity of the TO material}

The experiments were performed on cylindrical specimens made of electrically conductive nonmagnetic materials. Two series of cylindrical specimens of aluminum and bronze (with a specific electrical conductivity of $\gamma_{a l}=4.87 \cdot 10^{7} \mathrm{~S} / \mathrm{m}, \gamma_{b r}=2.75 \cdot 10^{7} \mathrm{~S} / \mathrm{m}$, respectively) with different diameters in the range of $34 \div 35 \mathrm{~mm}$ were used.

The excitation coil of the separate transmit-receive probe with the $W_{1}=176$ was fed a pulse signal from the generator, which had amplitude $15 \mathrm{~V}$, period $T_{p}=10^{-2} \mathrm{~s}$, duration $\tau=10^{-3} \mathrm{~s}$. The signal model could be represented by the expression [34]:

$u(t)= \begin{cases}15 V, & t_{1}+k T_{p}<t<t_{1}+\tau+k T_{\mathrm{p}} \\ 0 V, & t_{1}+\tau+k T_{p}<t<t_{1}+(k+1) T_{p}, k=0,1,2 \ldots\end{cases}$

The signal from the measuring ECP coil was fed into the ADC to form a set $u[j], j=\overline{1, \ldots 2400}$. The set was performed with the period $T_{p}=0.5 \cdot 10^{-6} \mathrm{~s}$. The $u[j]$ values were transferred to a personal computer for further analysis.

The graph of the PEC probe signal phase (curve 1) obtained in the case of inspecting the aluminum specimen with a diameter of $d=34 \mathrm{~mm}$ is presented in Fig. 8.

Fig. 9 shows a graph of the dependence of $f(d)$ for aluminum (curve 1) and bronze (curve 2) specimens, and also contains their linear trends (curves 3 and 4, respectively). Analysis of these graphs indicates that the change in the diameter of the specimens leads to a change in the frequency of the ECP signal, which is close to linear. Also, the linear dependence on the diameter can be traced for the signal attenuation coefficient (Fig. 10, curve 1 is for a series of aluminum specimens, curve 2 for bronze).

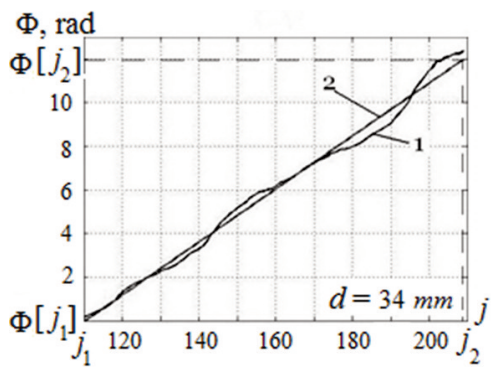

Fig. 8. Fragment of the pulsed ECP signal phase (1) and its trend (2).

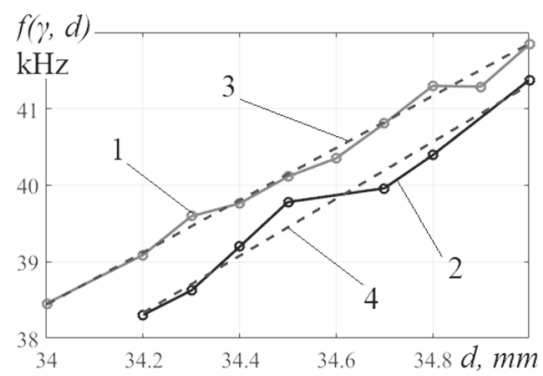

Fig. 9. Dependence graphs $f(d)(1,2)$ and their linear trends $(3,4)$. 


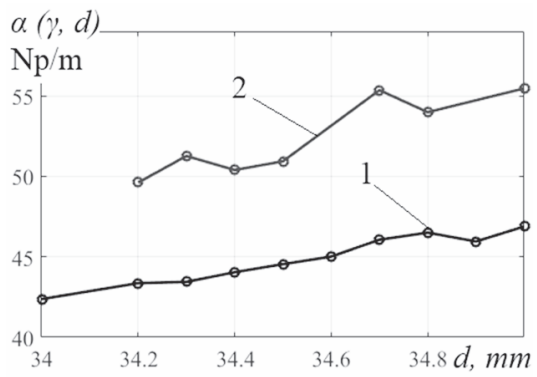

Fig. 10. Dependence graphs $\alpha(d)$.

Analysis of graphs in Fig. 10 indicates not only the possibility of sorting materials by electrical conductivity, but also the possibility of estimating the diameter values of the TO in the event of precalibration of the PEC testing system.

\section{CONCLUSION}

Our review of the existing literature showed that modern pulsed eddy current (PEC) inspection is typically carried out in aperiodic mode, yet at the same time, the unstable characteristic points of the EC signal usually used as informative parameters may restrict the potential of this excitation mode due to significant measurement errors.

The objective of this study, therefore, was to consider the use of the oscillatory mode in PEC testing. Our analysis of the processes of PEC probe signal formation in this excitation mode allowed us to determine the conditions of attenuation of harmonic oscillations, suggesting the use of its natural frequency and attenuation as informative signal parameters. Our theoretical modelling supported computer experiments to estimate the interrelation of informative signal parameters with parameters and characteristics of a tested object.

Next, we considered methods for improving the accuracy of determining the attenuation and natural frequency of the PEC probe signal in the oscillatory mode. The proposed methods were based on signal parameter determination according to the trends of ACS and FSC. Discrete Hilbert transformation and feature extraction based on the analysis of both the linear trend of the phase and exponential amplitude approximation of PEC probe signals the amplitude served as the basis for the developed method of processing and analysis of informative parameters of probe signals into pulse excitation. The technique so developed can be implemented as part of PEC testing tools, and autonomously for model experiments. We verified its efficiency by modeling the determination of the attenuation and the frequency of natural oscillations of the ECP signal with Gaussian noise.

Moreover, we performed experimental studies of the proposed informative parameters for pulsed eddy current control. The results confirmed the possibility of using the natural frequency and the attenuation coefficient of the probe signal in eddy current testing of aviation materials, i.e. testing of materials' electrical conductivity and estimation of the thickness of a dielectric coating. We established experimentally that during the testing of dielectric coating thickness on the substrate made of different materials, the attenuation of the ECP signal depends on the thickness and the magnetic permeability of the substrate material. The absolute error in determining the coating thickness on a steel substrate by the attenuation coefficient by the proposed method did not exceed $0.005 \mathrm{~mm}$, or $0.004 \mathrm{~mm}$ in the case of aluminum and bronze. The absolute error in determining the coating thickness on aluminum and bronze substrate by the natural oscillation frequency of the ECP signal did not exceed $0.03 \mathrm{~mm}$.

Overall, we reach the general conclusion that using the PEC technique in the oscillatory mode offers a promising avenue to expand the theoretical basis of ECT feature extraction. 


\section{REFERENCES}

[1] McMaster, R.C. and Mester, M.L., Eds., 1986, Nondestructive Testing Handbook: Electromagnetic Testing (Eddy current, Flux leakage and Microwave Nondestructive Testing). Second edition, American Society for NDT, USA.

[2] Ostash, O., Fedirko, V., Uchanin, V., Bychkov, S., Moliar, O., Semenets, O., Kravets, V. and Derecha, V., 2007, Mekhanika ruinuvannia i mitsnist materialiv [Fracture mechanics and strength of materials] (in Ukrainian), Vol. 9. Mitsnist i dovhovichnist materialiv litaka ta konstruktyvnykh elementiv [Strength and durability of airplane materials and structural elements] (in Ukrainian), Lviv, Spolom.

[3] Uchanin, V., 2013, Nakladni vykhrostrumovi peretvorjuvachi podvijnogho dyferencijuvannja [Surface Eddy Current Double Differentiation Sensors] (in Ukrainian), Lviv, Spolom.

[4] Baldev, R., Jayakumar, T. and Thavasimuthu, M., 2002, Practical non-destructive testing, Woodhead Publishing, India.

[5] Johnson, M.J., 1997, Pulsed eddy-current measurements for materials characterization and flaw detection, University of Surrey, UK.

[6] Waidelich, D.L., 1954, "Coating Thickness Measurement Using Pulsed Eddy Currents," Proceedings of the National Electronics Conference, 10, pp. 500-507.

[7] Waidelich, D.L., 1955, "Pulsed Eddy Currents Gauge Plating Thickness", Electronics, 28(11), pp. 146-147.

[8] Waidelich, D.L., 1958, "Reduction of Probe-Spacing Effect in Pulsed Eddy Current Testing", ASTM, Symp. on Non-Destructive Tests in the Field of Nuclear Energy, 223, pp. 191-200.

[9] Renken, C.J. and Myers, R.G., 1959, A Double Pulsed Eddy Current Testing System, University of Michigan, USA.

[10] Renken, C.J. and Myers, R.G., 1960, Metal Resistivity Measuring Device, USA, Patent no. 2965840.

[11] Shkarlet, Yu.M, and Russkevych, Yu.N., 1969, Ympulsnyi ynduktsyonnyi sposob yzmerenyia parametrov yzdelyi [Pulsed induction method of measuring product parameters] (in Russian), USSR, Inv. cert. 238856.

[12] Vasic, D., Bilas, V. and Ambrus. D., 2003, "Pulsed Eddy-Current Nondestructive Testing of Ferromagnetic Tubes," Proceedings of the 20th IEEE Instrumentation Technology Conference, (Cat. No.03CH37412), 2, pp. 1120-1125. doi: 10.1109/IMTC.2003.1207928.

[13] Morris, R.A., 1975, "Quantitative Pulsed Eddy Current Analysis," Proc. of the 10th Symposium on NDE, pp. 90-97.

[14] Thyagarajan, K., Maxfield, B., Balasubramaniam, K. and Krishnamurthy C.V., 2008, "Pulsed Eddy Current Imaging of Corrosion Pits," Proc. National Seminar on Non-Destructive Evaluation, Dec. 7-9, 2006, Hyderabad.

[15] Plotnikov, Y. and Bantz, W.J., 2005, "Subsurface defect detection in metals with pulsed eddy current," AIP Conference Proceedings 760, 447. doi: 10.1063/1.1916710.

[16] Cadeau, T. and Krause, T.W., 2009, "Pulsed eddy current probe design based on transient circuit analysis," AIP Conference Proceedings 1096, 327. doi: 10.1063/1.3114222.

[17] Yang, G., Tamburrino, A., Udpa, L. and Udpa, S., 2010, "Pulsed Eddy-Current Based Giant Magnetoresistive System for the Inspection of Aircraft Structures,” IEEE Trans. Magn., 46(3), pp. 910-917. doi: 10.1109/TMAG.2009.2032330.

[18] Sophian, A. and Tian, G. Y., 2005, "Defect classification using a new feature for pulsed eddy current sensors," NDT\&E International, 38(1), pp. 77-82. doi: 10.1016/j.ndteint.2004.06.001.

[19] Sophian, A., Tian, G. Y., Taylor, D. and Rudlin, J., 2005, "Wavelet-based PCA defect classification and quantification for pulsed eddy current NDT," IEE Proc.-Sci. Meas. Technol., 152(4), pp. 141148. doi: 10.1049/ip-smt:20045011. 
[20] Thompson, D.O. and Chimenti, D.E., Eds., 1998, Quantitative Assignment of Corrosion in Aircraft Structures Using Scanning Pulsed Eddy Current, Plenum Press, New York, NY.

[21] Morozov, M., Tian, G.Y. and Withers, P. J., 2010, “The pulsed eddy current response to applied loading of various aluminum alloys," NDT\&E International, 43, pp. 493-500. doi: 10.1016/j.ndteint.2010.05.004.

[22] He, Y., Zhang, H., Simm, A. and Jackson, P., 2012, "Steel Corrosion Characterization Using Pulsed Eddy Current Systems,” IEEE Sensors Journal, 12(6), pp. 2113-2120, doi: 10.1109/JSEN.2012.2184280.

[23] Lai, Sh., Chen, H. and Fu, Y., 2013, "Buried Crack Detection in Aircraft Multi-layer Structure Based on Pulsed Eddy Current," Applied Mechanics and Materials, 330, pp. 536-541. doi: 10.4028/www.scientific.net/AMM.330.536.

[24] He, Y., Luo, F., Pan, M., Weng, F., Hu, X., Gao, J. and Liu, B., 2010, "Pulsed eddy current technique for defect detection in aircraft riveted structure," NDT\&E International, 43(2), pp. 176181. doi: 10.1016/j.ndteint.2009.10.010.

[25] Technical Committee: ISO/TC 135/SC 4 Eddy current testing, 2017, Pulsed eddy current testing of ferromagnetic metallic components, BS ISO 20669:2017.

[26] Buchma, I.M., Repetylo, T.M. and Ferchuk, K.V. 2015, Zasoby vykhrostrumovoi diahnostyky koroziinoho stanu stalevykh lystovykh konstruktsii [Aids of eddy current diagnostics of corrosion condition of steel sheet structures] (in Ukrainian), Lviv Polytechnic Publishing House, Lviv.

[27] Korn, G.A. and Korn, T.M., 1968, Mathematical Handbook for Scientists and Engineers, Published by McGraw-Hill Book Company, New York, NY.

[28] Bendat, J. S., and Piersol, A. G., 2010, Random Data: Analysis and Measurement Procedures, Wiley, Hoboken, NJ.

[29] Poularikas, A.D., 2010, Transforms and Applications Handbook, CRC Press LLC, Taylor \& Francis Group, Boca Raton, New York, NY.

[30] Lysenko, I., Eremenko, V., Kuts, Y., Protasov, A. and Uchanin, V., 2020, "Advanced Signal Processing Methods for Inspection of Aircraft Construction Materials," Transactions on Aerospace Research, 259(2), pp. 27-35. doi: 10.2478/tar-2020-0008.

[31] Kuts, Y., Protasov, A., Lysenko, I. and Dugin, O., 2018, "Analysis of the uncertainty of measurement in pulsed eddy current signal evaluation," Proc. of 12th European Conference on NonDestructive Testing (ECNDT 2018), June 11-15, 2018, Sweden, The e-Journal of Nondestructive Testing, 23(8), pp. 1-8.

[32] Kuts, Y., Protasov, A., Lysenko, I., Alexiev, A. and Dugin O., 2019, "Optimization of Analysis Time of Pulsed Eddy Current Non-destructive Testing Signals" (in Russian), Bulgarian Society for NDT, Int. Journal “NDT Days”, 2(1), pp. 58-63. https:/www.bg-s-ndt.org/journal/vol2/JNDTDv2-n1-a07.pdf

[33] Dugin, O., Kuts, Y., Lysenko, I. and Protasov, A., 2016, "Improvement of the Eddy Current Method of Non-Destructive Testing with Pulsed Mode Excitation," Proc. of 19th World Conference on Non-Destructive Testing (WCNDT 2016), June 13-17, 2016, Germany, The e-Journal of Nondestructive Testing, 21(7), pp. 1-8.

[34] Lysenko, Y., Kuts, Y., Dugin, A., Zakrevskii, A., 2016, "Analysis of an Eddy-Current Transducer with Impulsive Excitation in the Nondestructive Testing of Cylindrical Objects," Materials Science, 52(3), pp 431-437. doi: 10.1007/s11003-016-9975-4. 


\title{
WYKORZYSTANIE TECHNIKI IMPULSOWYCH PRĄDÓW WIROWYCH (PEC) WTRYBIE OSCYLACYJNYM DO ULEPSZENIA ALGORYTMÓW DO WYODRĘBNIENIA CECH W KONTROLI STRUKTURY SAMOLOTU
}

\begin{abstract}
Abstrakt
Przegląd istniejącej literatury wskazuje, że nowoczesna technika impulsowych prądów wirowych (PEC) do wykrywania wad w inspekcji konstrukcji lotniczych jest zwykle prowadzona w trybie aperiodycznym. Przy tym, niestabilne punkty charakterystyczne w sygnale prądów wirowych, które zwykle są używane jako parametry informacyjne, mogą ograniczać potencjał tego trybu wzbudzenia ze względu na znaczne błędy pomiarowe.

W niniejszym artykule rozważano zaawansowaną metodę PEC dla badań nieniszczących (NDT) opartą na trybie oscylacyjnym. W celu uzyskania warunków związanych z różnymi trybami oscylacji odpowiedzi sondy prądów wirowych, opracowano i przeanalizowano równoważny schemat układu „obiekt badany - sonda”. Jako parametry informacyjne dla sygnałów brano częstotliwość i współczynnik tłumienia drgań własnych. Tak powstały model matematyczny sygnałów pozwala na ocenę zależności proponowanych parametrów sygnałów od właściwości obiektu badanego.

Najpierw na podstawie wyników symulacji opracowano algorytmiczne oprogramowanie do wyznaczania i analizy dyskretnych charakterystyk amplitudowych i fazowych sygnałów PEC NDT. Analizowano błędy wyznaczania częstotliwości drgań własnych oraz współczynnika tłumienia, a także optymalny czas jego wyznaczania w celu minimalizacji możliwych błędów. Następnie, zaproponowane parametry informacyjne badano eksperymentalnie z wykorzystaniem zestawu próbek. Otrzymane wyniki potwierdzają możliwość zastosowania proponowanej metody do usprawnienia procedur inspekcyjnych związanych z pomiarami przewodności elektrycznej, parametrów geometrycznych oraz oceny rozmiarów wykrywanych defektów.
\end{abstract}

Słowa kluczowe: impulsowy prąd wirowy, częstotliwość drgania naturalnego, osłabienie, amplituda i właściwości sygnału fazowego 